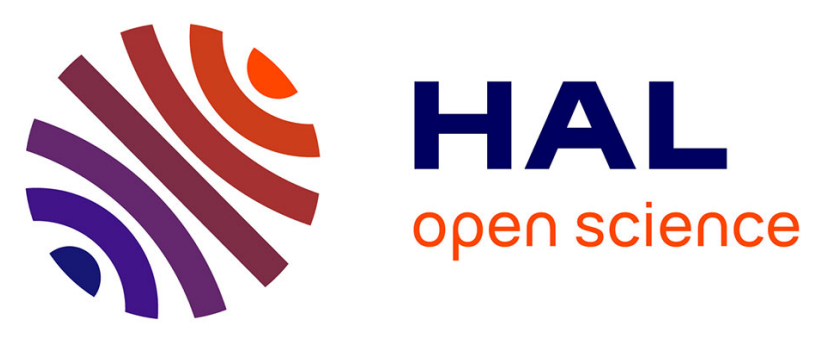

\title{
An Online Four-Dimensional HICxSEC-IMxMS Methodology for Proof-of-Concept Characterization of Antibody Drug Conjugates
}

Anthony Ehkirch, Valentina d'Atri, Florent Rouvière, Oscar Hernandez-Alba, Alexandre Goyon, Olivier Colas, Morgan Sarrut, Alain Beck, Davy Guillarme, Sabine Heinisch, et al.

\section{To cite this version:}

Anthony Ehkirch, Valentina d'Atri, Florent Rouvière, Oscar Hernandez-Alba, Alexandre Goyon, et al.. An Online Four-Dimensional HICxSEC-IMxMS Methodology for Proof-of-Concept Characterization of Antibody Drug Conjugates. Analytical Chemistry, 2018, 90 (3), pp.1578 - 1586. 10.1021/acs.analchem.7b02110 . hal-01767719

\author{
HAL Id: hal-01767719 \\ https://hal.science/hal-01767719
}

Submitted on 8 Oct 2020

HAL is a multi-disciplinary open access archive for the deposit and dissemination of scientific research documents, whether they are published or not. The documents may come from teaching and research institutions in France or abroad, or from public or private research centers.
L'archive ouverte pluridisciplinaire HAL, est destinée au dépôt et à la diffusion de documents scientifiques de niveau recherche, publiés ou non, émanant des établissements d'enseignement et de recherche français ou étrangers, des laboratoires publics ou privés. 


\title{
An online four-dimensional HICXSEC-IMxMS methodology for in- depth characterization of antibody drug conjugates.
}

\author{
Anthony EHKIRCH ${ }^{\ddagger}$, Valentina D’ATRI ${ }^{2}$, Florent ROUVIERE*, Oscar HERNANDEZ-ALBA ${ }^{1}$, Al- $^{*}$ \\ exandre GOYON², Olivier COLAS ${ }^{4}$, Morgan SARRUT33, Alain BECK4, Davy GUILLARME², Sabine \\ HEINISCH $3^{*}$, Sarah CIANFERANI ${ }^{*}$ \\ ${ }^{1}$ Laboratoire de Spectrométrie de Masse BioOrganique, Université de Strasbourg, CNRS, IPHC UMR 7178, 6700o \\ Strasbourg, France \\ ${ }^{2}$ School of Pharmaceutical Sciences, University of Geneva, University of Lausanne, CMU - Rue Michel-Servet, 1, 1206 \\ Geneva - Switzerland \\ ${ }^{3}$ Univ Lyon, CNRS, Université Claude Bernard Lyon 1, Ens de Lyon, Institut des Sciences Analytiques, UMR 5280, \\ 69100 VILLEURBANNE, France \\ ${ }^{4}$ IRPF - Centre d'Immunologie Pierre-Fabre (CIPF), Saint-Julien-en-Genevois, France
}

\begin{abstract}
There are currently two main techniques allowing the analytical characterization of interchain cysteine-linked antibody drug conjugates (ADCs) under non denaturing conditions, namely hydrophobic interaction chromatography (HIC) and native mass spectrometry. HIC is a chromatographic technique allowing the evaluation of drug load profile and the calculation of average drug to antibody ratio (DAR). Native mass spectrometry (MS) offers structural insights into multiple ADC critical quality attributes, thanks to accurate mass measurement. On-line coupling of both techniques can potentially be of great interest, but the presence of large amounts of non-volatile salts in HIC mobile phases make them non compatible with MS. Here, we present an innovative multidimensional analytical approach combining comprehensive online two dimensional chromatography that consists of HIC and size exclusion chromatography (SEC) to ion mobility and mass spectrometry (IM-MS) for performing analytical characterization of ADCs under non-denaturing conditions. Online hyphenation of non-denaturing $2 \mathrm{D}$-chromatography ( $\mathrm{HICxSEC})$ to $2 \mathrm{D}-\mathrm{IM}-\mathrm{MS}$ enabled comprehensive and streamlined characterization of both native and stressed ADC samples. The proposed $4 \mathrm{D}$ methodology could be more generally adapted for on-line all-in-one HICxSEC-IMxMS analysis of single protein or protein complexes analysis in non-denaturing conditions.
\end{abstract}

\section{INTRODUCTION}

Monoclonal antibodies (mAbs) and their related compounds make up the largest class in human therapeutics to treat various diseases. The success of mAbs stems from their high specificity and affinity, long circulating halflives, ability to induce immune cell effector response, and structural versatility. ${ }^{1}$ However, canonical mAbs often show a limited efficacy or face resistance, so several families of either armed antibodies (antibody drug conjugates, $\mathrm{ADCs}$ ) or bispecific mAbs (bsAbs) have been developed to overcome these limitations. ADCs are tripartite molecules consisting of a mAb onto which highly cytotoxic small molecules are conjugated by cleavable or non-cleavable linkers. They show better efficiency than canonical unconjugated $\mathrm{mAbs}$, due to the synergic effect of mAb specificity for its target and the efficacy of the highly cytotoxic drug. ${ }^{2}$ Many of these next generation antibody derivatives, including ADCs, have emerged from a better understanding of structure-function relationships, which have mainly been achieved thanks to state-of-the art mass spectrometry
(MS) and chromatographic methods. Indeed, ADCs are more complex than mAbs, because of the increased inherent micro-variability imparted by the addition of a variable number of drug-linkers. Several recent papers have extensively reviewed the advantages, drawbacks and complementarity of such approaches..$^{3-5}$ The analytical characterization of mAb-related compounds usually follows a multilevel workflow, where biopharmaceuticals are studied at the intact protein level (top level), after enzymatic digestion into smaller mAb sub-domains (middle-up level), or after proteolytic digestion to generate peptides and glycopeptides (bottom-up level). ${ }^{6}$ Middle- and bottom-up levels require preliminary sample treatment that can introduce artefact (increased deamidation, oxidation, generation of aggregates, etc.). Top level methods performed on intact mAbs require less sample handling and are thus of utmost interest. ${ }^{7}$

The development and optimization of ADCs rely on the continuous improvement of their analytical and bioanalytical characterization by assessing several critical quality attributes (CQA), ${ }^{8}$ namely the distribution and position of 
the cytotoxic drug, 9 the amount of naked antibody, the average drug to antibody (DAR) ratio, ${ }^{10}$ and the residual drug-linker and related product proportions. ${ }^{11}$ The average DAR represents the amount of payloads that can be delivered to the tumor cell and thus is directly linked to the toxicity and the safety of the ADC. The distribution of drugloads (i.e. the fraction of antibodies containing zero, one, two, three, $n$ drugs) is also an important characteristic, since the different isoforms may have different toxicological and pharmacological properties.

As conjugation technologies may result in a highly heterogeneous ADC product, with respect to the loading of cytotoxic drug species, their position on the $\mathrm{mAb}$ and the cleavability of the linker, there is no generic method allowing a complete analytical characterization of ADCs. The classical denaturing RPLC-MS methods fail for ADC characterization, due to the harsh mobile phase conditions employed in chromatography (acidic $\mathrm{pH}$, high proportion of organic solvent, elevated mobile phase temperature), which disrupt the noncovalent associations between ADC sub-domains. ${ }^{12}$ The benchmark methods to characterize drugload distribution and assess average DAR on ADCs are based on chromatography, and particularly hydrophobic interaction chromatography (HIC), which separate mAbs based on the increased hydrophobicity imparted to the antibody by the increased number of drug conjugates..$^{10,13-16}$ However, chromatographic methods that would both separate individual species and preserve the structure of the ADC, like HIC, are not directly amenable to online MS detection.

Up to now, there are two solutions that were suggested to hyphenate HIC with native MS. The first one consists in a time consuming off-line coupling performed by peak collection, manual desalting of the fractions and subsequent native MS or IM-MS analysis. ${ }^{17}$ A second alternative approach was recently proposed and it is based on the online combination of HIC and RPLC, using either fully comprehensive $^{18}$ or heart-cutting ${ }^{19}$ 2D-LC strategies. The online addition of an RPLC step allows i) the elimination of the non-volatile salts contained in the HIC mobile phase and ii) the improvement of the resolving power, due to the additional chromatographic dimension. ${ }^{20}$ However, the interchain cysteine-linked ADC samples are denaturated by the harsh RPLC conditions, ${ }^{17,21}$ leading to an indirect and more difficult characterization of the complex ADC samples.

Because of the need for robust, highly powerful and, if possible, non-denaturing analytical techniques to answer ADCs requirements, we present here a new analytical technique based on the hyphenation of on-line two-dimensional non-denaturing chromatography involving HIC in the first dimension and size exclusion chromatography (SEC) in the second one (i.e. HICxSEC), to non-denaturing mass spectrometry hyphenated to ion mobility (IM-MS) for intact protein therapeutics analysis. As benefits of nondenaturing MS and its hyphenation to ion mobility (IMMS) analysis have already been demonstrated for $m A b,{ }^{22}$ $\mathrm{ADC},{ }^{17,23,24}$ or $\mathrm{bsAb}^{17}$ characterization, we aimed here at a direct coupling of this powerful IM-MS strategy with nondenaturing chromatographic separation by HIC.

\section{EXPERIMENTAL SECTION}

\section{Reagents and materials}

All chemicals were purchased from Sigma-Aldrich : ammonium acetate (A1542), cesium iodide (21004), phosphoric acid (345245), 2-propanol (I9516), sodium chloride (S7653), sodium phosphate monobasic (S8282), sodium phosphate dibasic $\left(\mathrm{S}_{7907}\right)$. All the aqueous solutions were prepared using an ultra-pure water system (Sartorius, Göttingen, Germany). Brentuximab vedotin (Adcetris) was from Takeda.

\section{Preparation of thermally stressed ADC solution sam- ple}

A vial of $50 \mathrm{mg}$ freeze dried brentuximab vedotin was reconstituted under aseptic conditions with $10 \mathrm{ml}$ water to yield a $5 \mathrm{mg} / \mathrm{ml}$ solution. Next, $1 \mathrm{ml}$ of the solution was transferred in a sterile $1.5 \mathrm{ml}$ tube under a laminar flow hood 25 and incubated at $40{ }^{\circ} \mathrm{C}$ for 4 weeks.

\section{Instrumentation}

The LCxLC-IMxMS system consists in a combination of $\mathrm{H}$ Class and I-Class liquid chromatography systems hyphenated to a Synapt G2 HDMS Q-TOF mass spectrometer, both from Waters (Manchester, UK). In the first dimension, the $\mathrm{H}$-Class system includes a high-pressure quaternary solvent delivery pump, an autosampler with a flowthrough needle of $15 \mu \mathrm{L}$ equipped with an extension loop of $50 \mu \mathrm{L}$. In the second dimension, the I-class system includes a high-pressure binary solvent delivery pumps, a column manager composed of two independent column ovens and two 6-port high pressure two-position valves acting as interface between the two chromatographic separation dimensions. A single wavelength UV detector and a diode array detector both equipped with $500 \mathrm{~nL}$ flow-cell were used for the first and second dimension, respectively. The dwell volumes were about $425 \mu \mathrm{L}$ and $300 \mu \mathrm{L}$ for the first and the second dimensions, respectively. It should be noted that the dwell volume of the second dimension includes the volume of sample loops used at the interface (i.e. $200 \mu \mathrm{L}$ ). Measured extra-column volumes were $12 \mu \mathrm{L}$ and $17 \mu \mathrm{L}$ for the first and second dimensions, respectively. An external two position switching valve (Vici Valco Instruments, Houston, USA) was also placed prior to the mass spectrometer. Non-denaturing MS and ion mobility experiments were performed on a TWIMS-MS Synapt G2 HDMS instrument (Waters, Manchester, UK). Data acquisition and instrument control were performed with MassLynx V4.1 software (Waters). 2D-data (UV and TIC) were exported to Matlab $\mathrm{V}_{7.12 .0635}$ to construct $2 \mathrm{D}$-contour plots via house-made calculation routines. MS-Data were processed with Masslynx 4.1.

\section{Chromatographic conditions}

The HIC column was a MabPac HIC-10 (10o mm x $4.6 \mathrm{~mm}$, $5 \mu \mathrm{m}, 1000 \AA$ ) from Thermo Scientific, Cheshire, UK. The 
SEC column employed in the second dimension was an AdvanceBio SEC ( $50 \mathrm{~mm} \times 4.6 \mathrm{~mm}, 2.7 \mu \mathrm{m}, 300 \AA$ ) from Agilent Technologies, Wilmington, DE, USA.

For the HIC first dimension, the mobile phase A was composed of 2.5 $\mathrm{M}$ of ammonium acetate and o.1 $\mathrm{M}$ phosphate buffer $\left(\mathrm{Na}_{2} \mathrm{HPO}_{4}\right), \mathrm{pH}$ 7.o (adjusted with phosphoric acid), while the mobile phase $\mathrm{B}$ was composed of o.1 $\mathrm{M}$ phosphate buffer $\left(\mathrm{Na}_{2} \mathrm{HPO}_{4}\right.$ and $\left.\mathrm{NaH}_{2} \mathrm{PO}_{4}\right)$ with $\mathrm{pH} 7.0$ (adjusted with sodium hydroxide solution). The following gradient was employed in HIC: o to $90 \%$ B in $36 \mathrm{~min}$, 90 to $100 \% \mathrm{~B}$ in 21 min, followed by an isocratic step at $100 \%$ B for $8 \mathrm{~min}$ before re-equilibration during 25 minutes, for a total analysis time of $90 \mathrm{~min}$. The HIC experiment was conducted at a flow-rate of $100 \mu \mathrm{L} / \mathrm{min}$. Column temperature, wavelength and data acquisition rate were set at $30^{\circ} \mathrm{C}, 280 \mathrm{~nm}$ and 10 $\mathrm{Hz}$ respectively. The injection volume was $40 \mu \mathrm{L}$.

For the second chromatographic dimension in SEC, the separation was carried out in isocratic mode with an aqueous mobile phase composed of $100 \mathrm{mM}$ ammonium acetate at a flow-rate of $700 \mu \mathrm{L} / \mathrm{min}$. Column temperature, wavelength and data acquisition rate were set at $25^{\circ} \mathrm{C}, 210 / 280$ $\mathrm{nm}$ and $4 \mathrm{o} \mathrm{Hz}$ respectively. The analysis time of the second dimension run corresponds to the sampling time of the first dimension separation, namely $1.5 \mathrm{~min}$. A fraction of $0.45 \mathrm{~min}$ (from 0.42 to $0.87 \mathrm{~min}$ ) was sent to MS thanks to a switching valve, to limit salt contamination of the ESI source. A flow splitter divided the flow-rate by a factor 7 prior to entering MS (i.e. inlet flow of $100 \mu \mathrm{L} / \mathrm{min}$ ).

\section{Non-denaturing mass spectrometry conditions}

The Synapt G2 HDMS was operated in sensitive mode and positive polarity with a capillary voltage of $3.0 \mathrm{kV}$. To avoid disruption of weak non-covalent interactions, the sample cone and pressure in the interface region were set to $160 \mathrm{~V}$ and $6 \mathrm{mbar}$, respectively. Source and desolvation temperature were set to 100 and $450^{\circ} \mathrm{C}$, respectively. Desolvation and cone gas flows were set at 750 and $60 \mathrm{~L} / \mathrm{Hr}$, respectively. Acquisitions were performed in the $\mathrm{m} / \mathrm{z}$ range of $1000-10000$ with a $1.5 \mathrm{~s}$ scan time. External calibration was performed using singly charged ions produced by a $2 \mathrm{~g} / \mathrm{L}$ solution of cesium iodide in 2-propanol/water $(50 / 50 \mathrm{v} / \mathrm{v})$.

\section{Ion mobility mass spectrometry conditions}

For IM-MS measurements, the sample cone voltage was set to $100 \mathrm{~V}$ and the backing pressure of the source was $6 \mathrm{mbar}$. The Ar flow rate was $5 \mathrm{~mL} / \mathrm{min}$ and the trap collision energy was set at $4 \mathrm{~V}$ in the traveling-wave-based ion trap. Ions were thermalized with a constant He flow rate of 130 $\mathrm{mL} / \mathrm{min}$ before IM separation. The height and the velocity of the periodic waveform in the pressurized ion mobility cell were $40 \mathrm{~V}$ and $923 \mathrm{~m} / \mathrm{s}$, respectively. $\mathrm{N}_{2}$ was used as drift gas $(45 \mathrm{~mL} / \mathrm{min})$ providing a constant pressure of 2.75 mbar. Transfer collision energy was fixed to $2 \mathrm{~V}$ to extract the ions from the IM cell to the TOF analyzer. A calibration based on three different proteins (concanavaline A, pyruvate kinase and alcohol dehydrogenase) in non-denaturing conditions was used to perform collision cross section (CCS) calculation as previously described. ${ }^{26,27}$

\section{Average DAR calculation}

The average DAR value represents the sum of relative peak area for each DAR multiplied by its corresponding number of drugs. It was calculated from HIC chromatogram, by using Equation 1.

$$
D A R_{a v}=\frac{\sum_{0}^{8} k \cdot A_{k}}{\sum_{0}^{8} A_{k}}
$$

Where $k$ is the number of drugs and $A_{k}$ the HIC peak area of $\mathrm{DAR}_{\mathrm{k}}$.

\section{RESULTS AND DISCUSSION}

\section{Rationale for the $2 \mathrm{D}$-LC-IM-MS design and optimiza- tion of HICxSEC conditions}

HIC is nowadays considered as the reference technique for the analytical characterization of cysteine linked ADC in quality control laboratories. In theory, it allows the separation of the individual DARs on the basis of the number of attached drugs and their hydrophobicity. However, in many cases, the HIC profile is more complex than expected and it becomes difficult to interpret all the potential additional peaks, which could correspond either to positional isomers of DAR species, ${ }^{10}$ DAR species with an odd number of cytotoxic drugs, ${ }^{18}$ or other type of variants and degradation products.

Due to the high amount of non-volatile salts generally employed in HIC, it is not possible to directly combine this chromatographic method with MS detection to identify the peaks observed on the HIC profile. For this reason, there is a need for eliminating the salts employed in HIC, while keeping the non-denaturing advantages offered by this chromatographic approach. First, rather than employing ammonium sulfate as the major component of the mobile phase, ammonium acetate was selected in this study, as it is volatile and MS compatible in routine analysis. In addition, it was recently demonstrated that a highly similar HIC separation of commercial ADC can be obtained with both ammonium sulfate and ammonium acetate, assuming that the amount of salt was adjusted. ${ }^{14}$

Beyond HIC mobile phase modification, which remains insufficient for a straight hyphenation to MS, an additional chromatographic dimension (SEC) was added as on-line desalting step before the MS inlet (Figure 1). SEC was selected in this setup because it allows a size-based separation of the species, ${ }^{14}$ that would allow differentiation of the HIC salts (low molecular weights species of $<100 \mathrm{Da}$ ) and the different isoforms of the ADC (very high molecular weight species of $>150$, ooo Da).

In order to achieve HICxSEC hyphenation, it was necessary to optimize $2 \mathrm{D}$-conditions, starting with the same HIC separation as the one recently optimized in ${ }^{18}$. To achieve a very fast SEC separation, which is a prerequisite for on-line comprehensive $2 \mathrm{D}$-separation, a short $50 \mathrm{~mm}$ SEC column was employed at a flow rate corresponding to the maximum recommended inlet pressure $(0.7 \mathrm{~mL} / \mathrm{min})$. The use of an efficient stationary phase that minimizes non-specific interactions with the hydrophobic ADC species ${ }^{28}$ provided sufficient resolving power to discriminate HIC salts and ADC samples in the case of low injection volumes. With 1 
$\mu \mathrm{L}$ injected and a flow-rate of $700 \mu \mathrm{L} / \mathrm{min}$, ADC species (BV) and salts were indeed well separated, leading to symmetrical peaks and retention times of $0.59 \mathrm{~min}$ and 0.95 min respectively (Figure 2a).

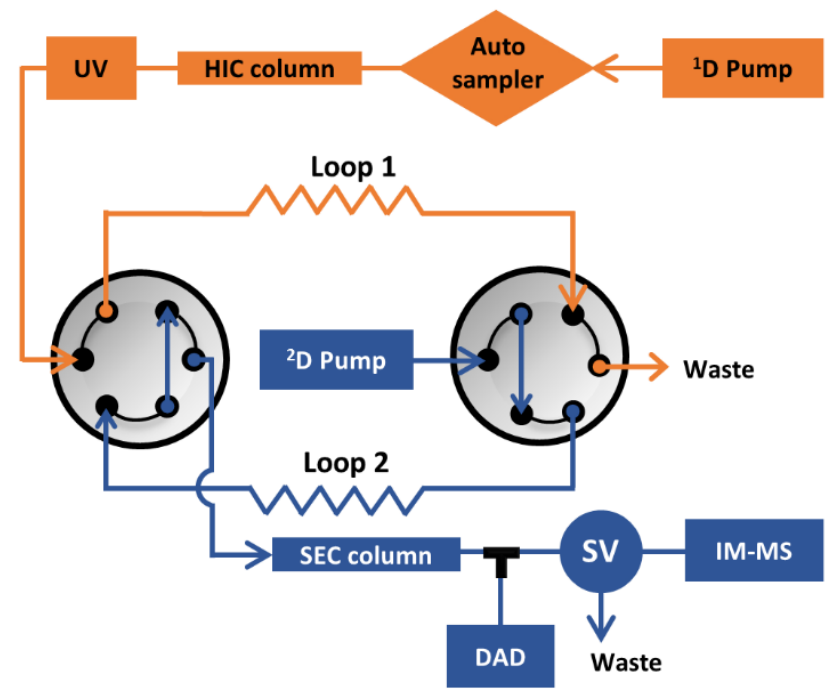

Figure 1. Schematic representation of HICxSEC-IM-MS setup. Abbreviations defined as UV: UV detector; DAD: diode array detector; SV: switching valve; IM-MS: ion mobility mass spectrometer

However, Figure 2a also shows strong peak distortion (broadening and tailing) for both species with 10 and $50 \mu \mathrm{L}$ injected, resulting in resolution decrease and separation time increase. In on-line $2 \mathrm{D}-\mathrm{LC}$, much larger injection volumes are required since the two separations are linked by the sampling time. As a result, the sampling time has to be long enough to achieve the separation in the second dimension $\left({ }^{2} \mathrm{D}\right)$ and short enough to send a sufficient number of fractions in ${ }^{2} \mathrm{D}$ while keeping the separation in the first dimension ( $\left.{ }^{1} \mathrm{D}\right)$. The effective resolution in ${ }^{1} \mathrm{D}$ can be strongly affected by under-sampling resulting from the necessity to send large fractions in the second dimension. In the meantime, as shown in Figure 2b, large injection volumes affect the peak shapes in the second dimension and hence the effective resolution. In our HIC conditions, the obtained minimum resolution was 1.5 . The loss in resolution should therefore not exceed 30\% (i.e. Rs $>1$ ) to maintain a sufficient separation between all pairs of peaks. According to the relationship established by Davis et al. to correct the resolution from under-sampling, ${ }^{29}$ a loss of $30 \%$ corresponds to a sampling rate of 2.7. Considering the ${ }^{1} \mathrm{D}$ peak widths (i.e. about $400 \mu \mathrm{l}$ ) obtained with the optimized HIC gradient, fractions of $150 \mu \mathrm{L}$ or less have to be sent in the second dimension. In case of $150 \mu \mathrm{L}$, a ${ }^{2} \mathrm{D}$ analysis time of $1.5 \mathrm{~min}$ was required to achieve the complete elution of the salts, leading to a ${ }^{1} \mathrm{D}$ flow-rate of $100 \mu \mathrm{L} / \mathrm{min}$ (i.e. 150/1.5). Reducing the injection volume and hence the separation time in ${ }^{2} \mathrm{D}$ could be a good option to increase the resolution in the second dimension. However, as can be shown in Figure 2a, the separation time is still $1.3 \mathrm{~min}$ with only $50 \mu \mathrm{L}$ injected, thereby leading to a lower $1 \mathrm{D}$-flow-rate (i.e. $40 \mu \mathrm{L} / \mathrm{min}$ ) and hence to a longer ${ }^{1} \mathrm{D}$-analysis time.
Furthermore, reducing the injection volume in ${ }^{2} \mathrm{D}$ would also lead to increase sample dilution. In light of the above considerations, a sampling time of $1.5 \mathrm{~min}$ and a ${ }^{1} \mathrm{D}$-flowrate of $100 \mu \mathrm{L} / \mathrm{min}$ were selected $(150 \mu \mathrm{L}$ injected in the second dimension). The resulting separation of a HIC fraction of BV on the SEC column is shown in Figure $2 \mathrm{~b}$. As shown, the baseline resolution between the two peaks was not obtained in these conditions, due to strong injection effects. The two vertical lines in Figure $2 \mathrm{~b}$ delimit a fraction with no salts, which could be sent to MS thanks to a two-position switching valve located between the SEC column outlet and the MS inlet. The rest of the SEC separation was sent to the waste (Figure 1). It is important to mention that, rather than a multiple heart-cutting methodology, a fully comprehensive on-line HICxSEC approach was considered in this study. The optimized $2 \mathrm{D}-\mathrm{HICxSEC}$ method was next hyphenated with high resolution native MS ( 3 dimensional approach), to achieve the identification of all the peaks observed in HIC for a cysteine linked ADC sample, without any denaturation. Finally, ion mobility (IM) was activated simultaneously to MS to have a conformational characterization of each HIC peak (4 dimensional approach). An overall schematic workflow of the fully comprehensive online HICxSEC-IMxMS strategy is provided in Figure 3. This HICxSEC-IMxMS configuration allowed maintaining the integrity of $\mathrm{HIC}{ }^{1} \mathrm{D}$-separation, while providing a global MS picture of the ADC sample under non-denaturing conditions within a single run, by disclosing the most exhaustive information. (a) 1D-SEC

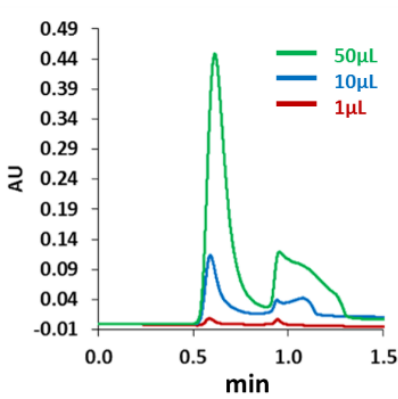

(b) HICXSEC

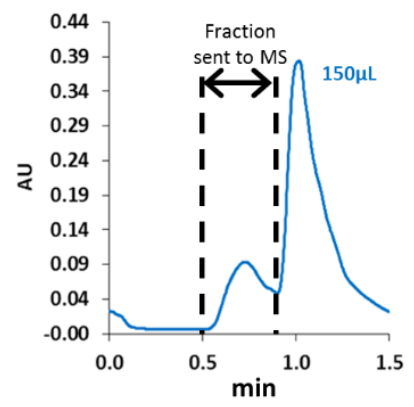

Figure 2. Effect of injection volume on the SEC separation of brentuximab vedotin and ammonium acetate: (a) $1 \mu \mathrm{L}, 10 \mu \mathrm{L}$ and $50 \mu \mathrm{L}$ of a sample containing $2.5 \mathrm{M}$ ammonium acetate and brentuximab vedotin $0.4 \mathrm{mg} / \mathrm{mL}$, injected in $1 \mathrm{D}$-SEC; (b) HICfraction of $150 \mu \mathrm{L}$ of brentuximab vedotin injected in ${ }^{2} \mathrm{D}$-SEC. Vertical lines delimit the SEC-fraction sent to MS. Other conditions given in the experimental section.

\section{HICxSEC-IMxMS analysis the reference cysteine- linked ADC, brentuximab vedotin (BV, Adcetris).}

As a proof-of-concept, we first analyzed BV, the reference cysteine linked ADC, on the previously described $4 \mathrm{D} \mathrm{HICx}-$ SEC-IMxMS system (Figure 3). Optimized HIC chromatogram was obtained in a first dimension for BV using ammonium acetate as mobile phase without any sample preparation (no deglycosylation, no buffer exchange, Figure 4a). Each 1.5 min long HIC segment was continuously sent 
onto the second dimension SEC column, enabling on-line, continuous fast buffer exchange of each individual highsalt containing HIC segment. All the SEC fractions were then continuously infused into a MS equipped with an IM separator via an electrospray ionization (ESI) source operating under non-denaturing conditions. IM conformational characterization and native MS provide the third and fourth dimensions of our approach, respectively.

As expected, five main peaks were detected after the ${ }^{1} \mathrm{D}$ HIC separation of BV (Figure 4a), which were all unambiguously identified by non-denaturing MS intact mass measurement (Figure $4 \mathrm{~b}$ right panel and Table 1). All detected species could be identified as drug load species (Do to D8) with a mass accuracy between 100-16o ppm, which is classical for intact ADC analysis in non-denaturing conditions on Q-TOF instruments ${ }^{17,23}$ and very good, considering the short acquisition time of only o.45 min. Of note, even minor HIC species like Do or D8 were clearly identified by non-denaturing MS. Therefore, average DAR determination is not anymore performed on the basis of species identification from HIC retention times, but on more accurate MS identification. For BV, an average DAR of 4.0 was unambiguously determined (Table 1), which is in agreement with expected values. ${ }^{17,30}$ To add an on-line additional dimension for conformational characterization, we next turned on the ion mobility of our MS, resulting in comprehensive $2 \mathrm{D}$-IM-MS analysis of BV in non-denaturing conditions (Figure $4 \mathrm{~b}$, left panel). Arrival time distributions (ATDs) of each individual species could be isolated in the IM cell, allowing conformational characterization through ${ }^{\mathrm{TW}} \mathrm{CCS}_{\mathrm{N}_{2}}$ calculations of each HICxSEC separated drug load species (Figure $4 \mathrm{~b}$, middle panel). IM analyses led to the determination of the conformational homogeneity of each individual HIC fraction, as already reported for off-line HIC-IMxMS analysis in non-denaturing conditions. ${ }^{17}$ Figure $4 \mathrm{~b}$ (left panel) presents the IMxMS contour plots of each individual HIC-detected species. A good agreement was obtained between ${ }^{\mathrm{TW}} \mathrm{CCS}_{\mathrm{N}_{2}}$ values obtained by $\mathrm{HICx}-$ SEC-IMxMS and those obtained by off-line injection of manually desalted BV (Table 1), demonstrating that the 2D-HICxSEC configuration does not affect BV global conformation. Altogether, our results demonstrate for the first time the ability to have a comprehensive analytical characterization of a cysteine-linked ADC within a single run, affording i) simultaneous drug load profile and quantitative average DAR assessment (HIC), ii) the unambiguous identification of the number of drug conjugations through accurate intact mass measurement in non-denaturing conditions (native MS), along with iii) conformational homogeneity assessment of each drug load species (native IM).

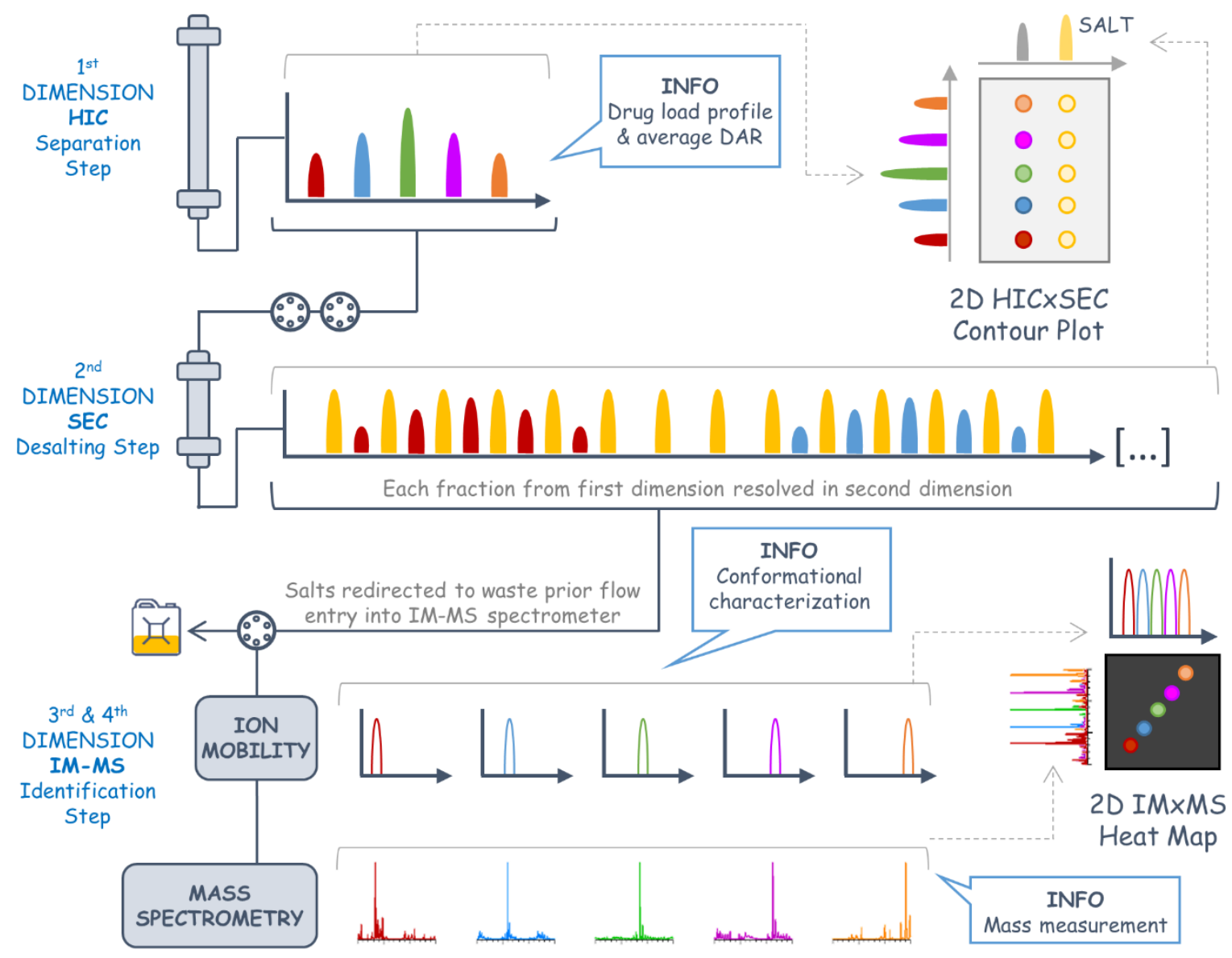

Figure 3. Flowchart of the analysis for brentuximab vedotin. 


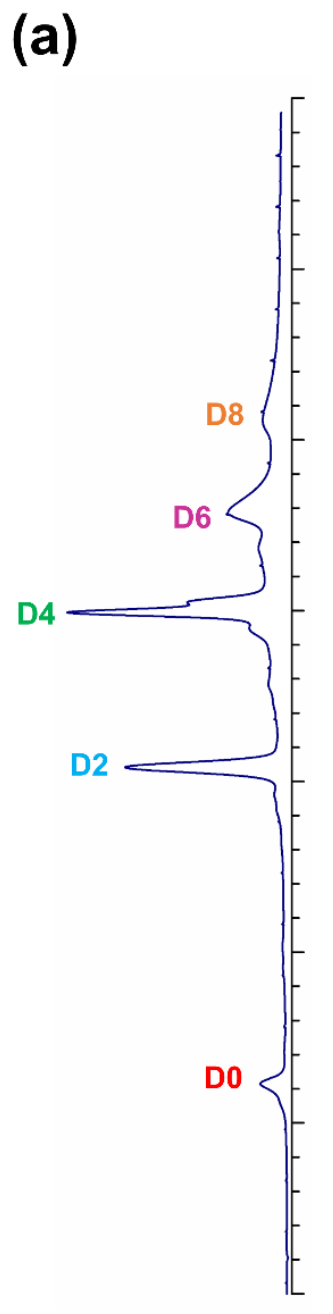

HIC profile

(b)
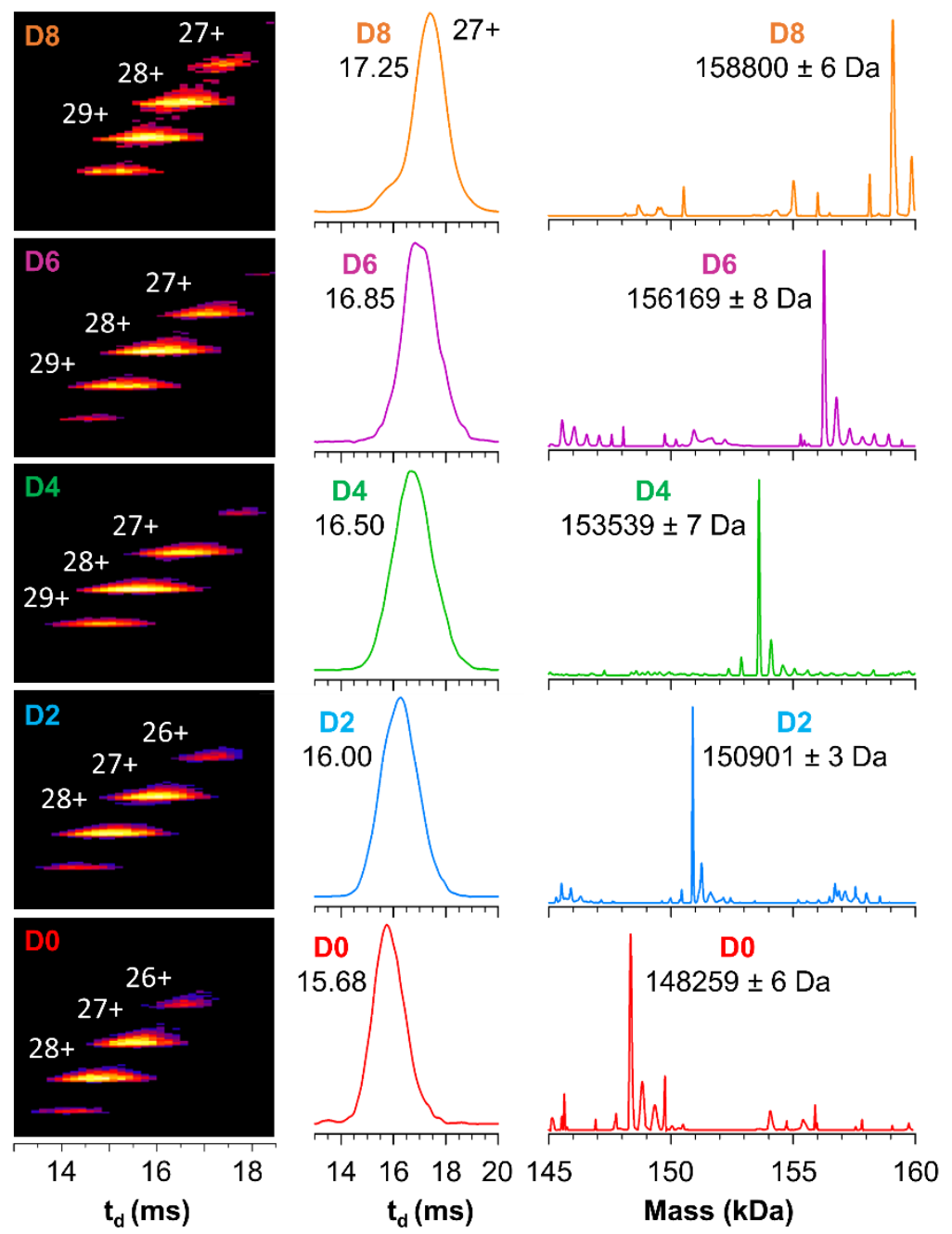

Figure 4. Online HICxSEC-IMxMS of brentuximab vedotin. HIC profile (a) and IM-MS characterization (b). For each individual DAR, zoom of the 13-18 $\mathrm{ms} \mathrm{t}_{\mathrm{d}}$ region of the driftscope plots (b, left panel), individual ATDs corresponding to the 27+ charge state (b, central panel), and deconvoluted native mass spectra (b, right panel) were represented.

\section{Application of HICxSEC-IMxMS in non-denaturing conditions for thermally stressed samples}

To highlight the possibilities and relevance of this new $4 \mathrm{D}$ approach involving chromatographic and mass spectrometric methods, we next compared intact BV and temperature stressed BV samples (see material and methods). A comparison of the HICxSEC 2 D-contour plots of stressed and non-stressed BV is shown in Figures $5 \mathrm{a}$ and $5 \mathrm{~b}$, respectively. As reported in one of our previous study in HICXRPLC-MS, ${ }^{18}$ the 2 D-HICxSEC contour plots of stressed BV clearly highlight increase in intensities of DARo species along with species eluted at retention times which are intermediate between DARo and DAR2, and between DAR2 and DAR4, respectively. In addition, the intensities of the DAR6 and DAR8 peaks significantly decrease, while the DARo peak increases (Table 1 and comparison of Figures $5 \mathrm{a}$ and $5 \mathrm{~b}$ ). The direct on-line coupling of non-denaturing MS to HICxSEC separation allowed first to accurately measure the molecular weights of all the compounds and to unambiguous identify DAR 1 and DAR3 odd DARs as species formed upon thermal stress (Figures $5 \mathrm{C}$ and $5 \mathrm{~d}$ ). Of note, only an averaged mass of all the glycoform could be measured for DAR1 and DAR 3 species in unstressed BV sample due to very low intensity MS signals hampering accurate mass measurements. Conversely, as DAR1 and $\mathrm{DAR}_{3}$ species because more abundant in stressed BV sample, accurate mass measurement of the most intense glycoform could be performed (Table 1). Thanks to MS identification of all the detected species, the average DAR calculated from the HIC chromatogram was reduced down to 2.8 in stressed conditions compared to 4.0 (Table 1), which is in agreement with previously published data. ${ }^{18}$ Simultaneously, on-line non-denaturing IM analysis allowed direct and unambiguous conformational characterization of odd DARs species (DAR 1 and $D_{A R}$ ) through their ${ }^{{ }^{T W}} \mathrm{CCS}_{\mathrm{N}_{2}}$ calculations (Table 1). 
Table 1. Summary of experimental values for the different DARs of non-stressed and stressed ADC: molecular weights obtained from mass spectra, experimental collision cross section $\left({ }^{\mathrm{TW}} \mathrm{CCS}_{\mathrm{He}}\right)$, HIC peak area and average DAR calculation. Abbreviations are defined as ND for not detected. Experimental masses of DARs were compared to the theoretical ones. Experimental collision cross sections obtained from centroid IM drift times were compared with predicted CCS $_{\mathrm{He}}$ calculated through the equation $\mathrm{CCS}=2.435^{*} \mathrm{M}^{2 / 3}$ for spherical proteins. ${ }^{27}$

\begin{tabular}{|c|c|c|c|c|c|c|c|c|c|c|c|}
\hline & $\begin{array}{c}\text { DAR } \\
\text { (G1F/GOF) }\end{array}$ & Do & D1 & D2 & D3 & D4 & D5 & D6 & D7 & D8 & \\
\hline & $\begin{array}{l}\text { Theoretical } \\
\text { mass (Da) }\end{array}$ & 148242 & 149559 & 150877 & 152195 & 153512 & 154830 & 156148 & 157465 & 158783 & \\
\hline \multirow{5}{*}{ 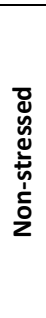 } & $\begin{array}{c}\text { Experimental } \\
\text { mass (Da) }\end{array}$ & $\begin{array}{c}148259 \\
\pm 6 \\
\end{array}$ & $\begin{array}{c}149756{ }^{*} \mathrm{Av}- \\
\text { erage mass }\end{array}$ & $\begin{array}{c}150901 \\
\pm 3\end{array}$ & $\begin{array}{c}152479 * A v- \\
\text { erage mass }\end{array}$ & $\begin{array}{c}153538 \pm \\
7 \\
\end{array}$ & ND & $\begin{array}{c}156169 \pm \\
8\end{array}$ & ND & $\begin{array}{c}158800 \pm \\
6 \\
\end{array}$ & \\
\hline & $\begin{array}{c}\text { Mass accuracy } \\
\text { (ppm) }\end{array}$ & 116 & - & 157 & - & 166 & - & 137 & - & 106 & \\
\hline & ${ }^{\mathrm{TW}} \mathrm{CCS}_{\mathrm{He}}\left(\mathrm{nm}^{2}\right)$ & 70.9 & - & 71.4 & - & 71.8 & - & 72.1 & - & 72.5 & \\
\hline & $\begin{array}{c}\text { Pred CCS } \\
\left(\mathrm{nm}^{2}\right)\end{array}$ & 68.2 & - & 69.0 & - & 69.8 & - & 70.6 & - & 71.4 & \\
\hline & $\begin{array}{c}\text { HIC peak area } \\
(\%)\end{array}$ & 5.8 & 1.8 & 24.1 & 4.3 & 32.8 & - & 21.5 & - & 9.7 & $\begin{array}{l}\text { Average } \\
\text { DAR } 4.0\end{array}$ \\
\hline \multirow{5}{*}{ 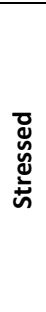 } & $\begin{array}{c}\text { Experimental } \\
\text { mass }(\mathrm{Da})\end{array}$ & $\begin{array}{c}148257 \\
\pm 7 \\
\end{array}$ & $\begin{array}{c}149588 \\
\pm 5 \\
\end{array}$ & $\begin{array}{c}150900 \\
\pm 5\end{array}$ & $\begin{array}{c}152221 \\
\pm 25 \\
\end{array}$ & $\begin{array}{c}153535 \pm \\
40\end{array}$ & ND & $\begin{array}{c}156167 \pm \\
21\end{array}$ & ND & $\begin{array}{c}158818 \pm \\
17\end{array}$ & \\
\hline & $\begin{array}{c}\text { Mass accuracy } \\
\text { (ppm) }\end{array}$ & 105 & 193 & 151 & 171 & 150 & - & 124 & - & 222 & \\
\hline & ${ }^{\mathrm{TW}} \mathrm{CCS}_{\mathrm{He}}\left(\mathrm{nm}^{2}\right)$ & 70.8 & 70.8 & 71.5 & 71.7 & 71.9 & - & 72.3 & - & 72.6 & \\
\hline & $\begin{array}{l}\text { Pred CCS } \\
\left(\mathrm{nm}^{2}\right)\end{array}$ & 68.2 & 68.6 & 69.0 & 69.4 & 69.8 & - & 70.6 & - & 71.4 & \\
\hline & $\begin{array}{c}\text { HIC peak area } \\
(\%)\end{array}$ & 13.5 & 10.6 & 25.9 & 7.3 & 33.4 & - & 8.2 & - & 1.1 & $\begin{array}{l}\text { Average } \\
\text { DAR } 2.8\end{array}$ \\
\hline
\end{tabular}

(a) Unstressed BV

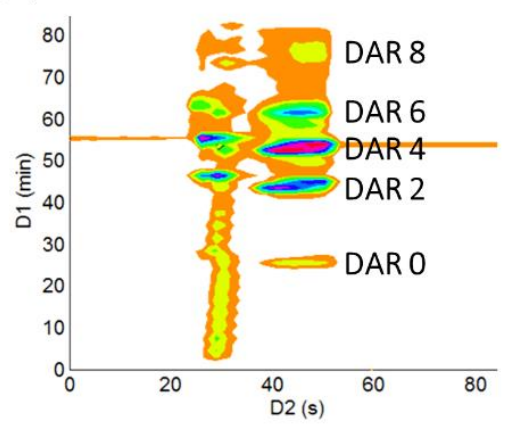

(b) Stressed BV

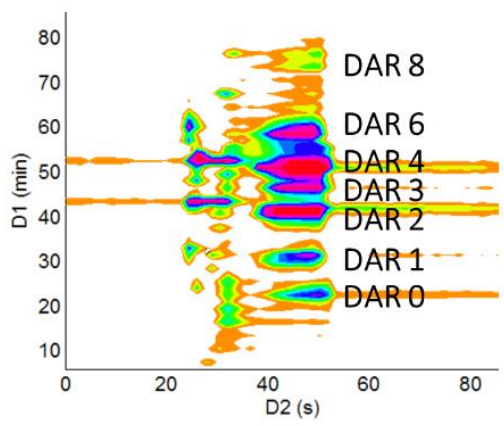

(c) DAR1 Not stressed - Stressed

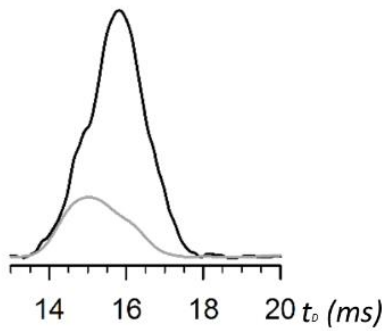

$149588 \pm 5 \mathrm{Da}$

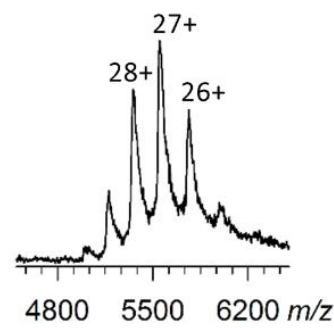

(d) DAR3 Not stressed Stressed

$152221 \pm 25 \mathrm{Da}$

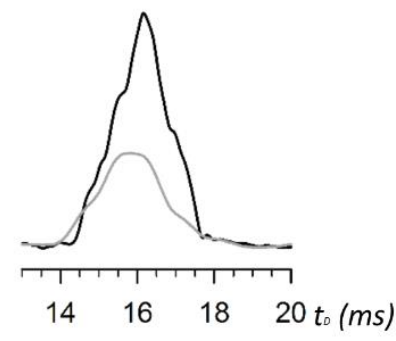

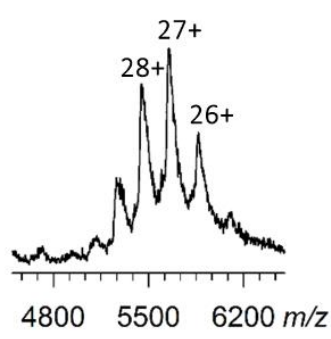

Figure 5. 2D-HICxSEC contour plots of brentuximab Vedotin (a) and stressed brentuximab vedotin (b). IM-MS structural characterization of odd DAR species (c-d) of stressed (black lines) and not stressed (grey lines) brentuximab vedotin. Individual ATDs corresponding to the $27+$ charge state (c-d, left panels), and native mass spectra (c-d, right panels) of DARı (c) and $\mathrm{DAR}_{3}(\mathrm{~d})$ were represented. 
In addition, comparison of normalized extracted ATDs of unstressed versus stressed BV clearly highlights the intensity increase of odd DAR species in forced degradation conditions (Figures $5 \mathrm{C}$ and $5 \mathrm{~d}$ ). Altogether, these results provide a first proof-of-concept for using a comprehensive $4 \mathrm{D}$ HICxSEC-IMxMS methodology to assess the structure of hinge cysteine ADCs.

\section{CONCLUSIONS}

We have presented here an innovative multidimensional analytical approach combining comprehensive on-line two dimensional chromatography (HICxSEC) to ion mobility and mass spectrometry (IM-MS) for performing analytical characterization of ADCs under non-denaturing conditions. On-line hyphenation of non-denaturing comprehensive $2 \mathrm{D}$-chromatography to $2 \mathrm{D}$-IMxMS enabled comprehensive and streamlined characterization of both native and stressed cysteine ADC samples. The combination of HIC and IMxMS using a $2 \mathrm{D}$-setup through a SEC desalting step allows obtaining in-depth and detailed information on ADC samples that cannot be reached from HIC-UV or nondenaturing mass spectrometry alone. The all-in-one analytical strategy described here permits a deep, straightforward and rapid characterization of complex ADC samples. In comparison to heart-cutting (or multiple heart-cutting) procedure, the most exhaustive information can be reached from the investigated sample using the comprehensive $2 \mathrm{D}$-strategy. As example, DARı and DAR3 species were observed with the comprehensive $2 \mathrm{D}$-approach, while this will probably not be the case with a heart-cutting approach. Such approach would be of great interest for example to assess the structure of ADCs derived from reduced interchain Cysteine and chemically crosslinked ("rebridged").31-33

The ability to have an on-line direct coupling of HIC to non-denaturing MS using 4D HICxSEC-IMxMS technique will have a strong impact on the analytical characterization of $A D C s$ and next generation empowered ADC formats like bispecific ADCs or dual ADCs as well as more generally for proteins. ${ }^{34}$ Several ADC quality attributes required for process and formulation development, routine lot-release, and stability testing can be monitored within one unique run using our $4 \mathrm{D}$ HICxSEC-IMxMS methodology. First, the gold standard HIC profile allows unambiguous drug load profile assessment. Its on-line hyphenation to non-denaturing MS (through on-line fast SEC desalting) brings the unique advantage of a clear and unambiguous identification of each chromatographic peak, through an accurate high resolution mass measurement along with conformational IM-MS characterization. As a result, the identification of each DAR species is straightforward and subsequent average DAR assessment more accurate. In addition, drug load profiles are obtained without any extensive sample preparation from the HIC chromatogram. Finally, the conformational IM separation allows global conformational homogeneity assessment of each peak. Altogether, the described ${ }_{4} \mathrm{D}$ HICxSEC-IMxMS approach could be proposed as the first multi-attribute method 35 in non-denatur- ing conditions for intact cysteine-linked ADC characterization that combines the power of chromatographic separation to the specificity of mass spectrometric identification.

Our innovative $4 \mathrm{D}$ HICxSEC-IMxMS can potentially be extended to the analysis of several other protein families, as HIC is a robust standard analytical method for protein analysis which preserves their biological activity. ${ }^{34}$ For instance, HIC is widely used to study post-translational modifications of proteins and drug-protein interactions. Recently, HIC has also been off-line combined to bottom up RPLC-MS/MS proteomics for single proteins or protein complexes analysis. ${ }^{36-38}$ In this context, our on-line $4 \mathrm{D}$ methodology could be envisioned for the on-line bottom up LC-MS/MS analysis of protein complexes in non-denaturing conditions. In addition, the first HIC dimension could be replaced by any other non-denaturing chromatographic methods like ion exchange (IEX) or size exclusion chromatography (SEC), enlarging the possibilities offered by our approach. More generally, the developed $4 \mathrm{D} \mathrm{HICx}$ SEC-IMxMS methods will open new ways for single proteins or protein complexes analysis in non-denaturing conditions.

\section{AUTHOR INFORMATION}

\section{Corresponding Author}

* sabine.heinisch@univ-lyonı.fr

* sarah.cianferani@unistra.fr

\section{Author Contributions}

$\$$ These authors contributed equally.

\section{Funding Sources}

This work was supported by the CNRS, the Université de Strasbourg, the Université de Lyon, the Agence Nationale de la Recherche (ANR) and the French Proteomic Infrastructure (ProFI; ANR-10-INBS-08-03), the Swiss National Science Foundation (fellowship 31003A_159494).

\section{ACKNOWLEDGMENT}

We thank GIS IBiSA and Région Alsace for financial support in purchasing a Synapt G2 HDMS instrument. A. Ehkirch acknowledges Syndivia for funding his $\mathrm{PhD}$ fellowship. Authors would like to thank David Lascoux (Waters) for his kind support and valuable assistance. Finally, the authors wish to thank Waters for the loan of $2 \mathrm{D}$-LC instrumentation used in this work.

\section{REFERENCES}

(1) Beck, A.; Goetsch, L.; Dumontet, C.; Corvaïa, N. Nat. Rev. Drug Discov. 2017, 16, 315-337.

(2) Ornes, S. Proc. Natl. Acad. Sci. 2013, 110, 13695-13695.

(3) Beck, A. MAbs 2014, 6, 30-33.

(4) Alley, S. C.; Anderson, K. E. Curr. Opin. Chem. Biol. 2013, 17, 406-411.

(5) Fekete, S.; Guillarme, D.; Sandra, P.; Sandra, K. Anal. Chem. 2016, 88, 480-507.

(6) Beck, A.; Terral, G.; Debaene, F.; Wagner-Rousset, E.; Marcoux, J.; Janin-Bussat, M.-C.; Colas, O.; Dorsselaer, A. Van; Cianférani, S. Expert Rev. Proteomics 2016, 13, 157-183. 
(7) Yang, Y.; Wang, G.; Song, T.; Lebrilla, C. B.; Heck, A. J. R. MAbs 2017, 9, 638-645.

(8) Wakankar, A.; Chen, Y.; Gokarn, Y.; Jacobson, F. S. MAbs 2011, 3, 161-172.

(9) Janin-Bussat, M.-C.; Dillenbourg, M.; Corvaia, N.; Beck, A.; Klinguer-Hamour, C. J. Chromatogr. B 2015, 981-982, 9-13.

(10) Le, L. N.; Moore, J. M. R.; Ouyang, J.; Chen, X.; Nguyen, M. D. H.; Galush, W. J. Anal. Chem. 2012, 84, 7479-7486.

(11) Birdsall, R. E.; McCarthy, S. M.; Janin-Bussat, M. C.; Perez, M.; Haeuw, J.-F.; Chen, W.; Beck, A. MAbs 2016, 8, 306-317.

(12) Fekete, S.; Veuthey, J.-L.; Beck, A.; Guillarme, D. J. Pharm. Biomed. Anal. 2016, 130, 3-18.

(13) Rodriguez-Aller, M.; Guillarme, D.; Beck, A.; Fekete, S. J. Pharm. Biomed. Anal. 2016, 118, 393-403.

(14) Cusumano, A.; Guillarme, D.; Beck, A.; Fekete, S. J. Pharm. Biomed. Anal. 2016, 121, 161-173.

(15) Ouyang, J. In Antibody-Drug Conjugates; Ducry, L., Ed.; Methods in Molecular Biology; Humana Press: Totowa, NJ, 2013; Vol. 1045, pp 275-283.

(16) Haverick, M.; Mengisen, S.; Shameem, M.; Ambrogelly, A. MAbs 2014, 6, 852-858.

(17) Debaene, F.; Bœuf, A.; Wagner-Rousset, E.; Colas, O.; Ayoub, D.; Corvaïa, N.; Van Dorsselaer, A.; Beck, A.; Cianférani, S. Anal. Chem. 2014, 86, 10674-10683.

(18) Sarrut, M.; Corgier, A.; Fekete, S.; Guillarme, D.; Lascoux, D.; Janin-Bussat, M.-C.; Beck, A.; Heinisch, S. J. Chromatogr. B 2016, 1032, 103-111.

(19) Birdsall, R. E.; Shion, H.; Kotch, F. W.; Xu, A.; Porter, T. J.; Chen, W. MAbs 2015, 7, 1036-1044.

(20) Stoll, D.; Danforth, J.; Zhang, K.; Beck, A. J. Chromatogr. $B$ 2016, 1032, 51-60.

(21) Valliere-Douglass, J. F.; McFee, W. A.; Salas-Solano, O. Anal. Chem. 2012, 84, 2843-2849.

(22) Beck, A.; Sanglier-Cianférani, S.; Van Dorsselaer, A. Anal. Chem. 2012, 84, 4637-4646.

(23) Marcoux, J.; Champion, T.; Colas, O.; Wagner-Rousset, E.; Corvaïa, N.; Van Dorsselaer, A.; Beck, A.; Cianférani, S. Protein Sci. 2015, 24, 1210-1223.

(24) Botzanowski, T.; Erb, S.; Hernandez-Alba, O.; Ehkirch, A.; Colas, O.; Wagner-Rousset, E.; Rabuka, D.; Beck, A.; Drake, P. M.; Cianferani, S. MAbs 2017, doi: 10.108o/19420862.2017.1316914.

(25) Sanders, E. R. J. Vis. Exp. 2012, No. 63, 1-12.
(26) Salbo, R.; Bush, M. F.; Naver, H.; Campuzano, I.; Robinson, C. V.; Pettersson, I.; Jørgensen, T. J. D.; Haselmann, K. F. Rapid Commun. Mass Spectrom. 2012, 26, 1181-1193.

(27) Bush, M. F.; Hall, Z.; Giles, K.; Hoyes, J.; Robinson, C. V.; Ruotolo, B. T. Anal. Chem. 2010, 82, 9557-9565.

(28) Goyon, A.; Beck, A.; Colas, O.; Sandra, K.; Guillarme, D.; Fekete, S. J. Chromatogr. A 2017, 1498, 80-89.

(29) Davis, J. M.; Stoll, D. R.; Carr, P. W. Anal. Chem. 20o8, 8o, 461-473.

(30) Sievers, E. L.; Senter, P. D. Annu. Rev. Med. 2013, 64, 1529.

(31) Badescu, G.; Bryant, P.; Bird, M.; Henseleit, K.; Swierkosz, J.; Parekh, V.; Tommasi, R.; Pawlisz, E.; Jurlewicz, K.; Farys, M.; Camper, N.; Sheng, X.; Fisher, M.; Grygorash, R.; Kyle, A.; Abhilash, A.; Frigerio, M.; Edwards, J.; Godwin, A. Bioconjug. Chem. 2014, 25, 1124-1136.

(32) Behrens, C. R.; Ha, E. H.; Chinn, L. L.; Bowers, S.; Probst, G.; Fitch-Bruhns, M.; Monteon, J.; Valdiosera, A.; Bermudez, A.; Liao-Chan, S.; Wong, T.; Melnick, J.; Theunissen, J.-W.; Flory, M. R.; Houser, D.; Venstrom, K.; Levashova, Z.; Sauer, P.; Migone, T.S.; van der Horst, E. H.; Halcomb, R. L.; Jackson, D. Y. Mol. Pharm. 2015, 12, 3986-3998.

(33) Bryant, P.; Pabst, M.; Badescu, G.; Bird, M.; McDowell, W.; Jamieson, E.; Swierkosz, J.; Jurlewicz, K.; Tommasi, R.; Henseleit, K.; Sheng, X.; Camper, N.; Manin, A.; Kozakowska, K.; Peciak, K.; Laurine, E.; Grygorash, R.; Kyle, A.; Morris, D.; Parekh, V.; Abhilash, A.; Choi, J.; Edwards, J.; Frigerio, M.; Baker, M. P.; Godwin, A. Mol. Pharm. 2015, 12, 1872-1879.

(34) O'Connor, B. F.; Cummins, P. M. 2017; Vol. 681, pp 355363.

(35) Rogers, R. S.; Nightlinger, N. S.; Livingston, B.; Campbell, P.; Bailey, R.; Balland, A. MAbs 2015, 7, 881-890.

(36) Rackiewicz, M.; Große-Hovest, L.; Alpert, A. J.; Zarei, M.; Dengjel, J. J. Proteome Res. 2017, acs.jproteome.7booo15.

(37) Chen, B.; Peng, Y.; Valeja, S. G.; Xiu, L.; Alpert, A. J.; Ge, Y. Anal. Chem. 2016, 88, 1885-1891.

(38) Xiu, L.; Valeja, S. G.; Alpert, A. J.; Jin, S.; Ge, Y. Anal. Chem. 2014, 86, 7899-7906. 


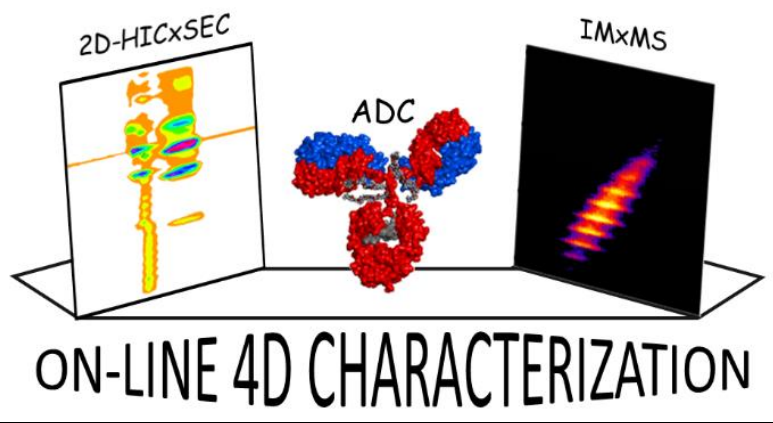

